Revista Internacional de Sociología (RIS)

Vol.67, N 2, Mayo-Agosto, 413-433, 2009

ISSN: $0034-9712$

DOI: $10.3989 / R I S .2008 .05 .11$

\title{
LA NEORRURALIDAD Y SUS SIGNIFICADOS El caso de Navarra
}

\author{
NEO-RURALITY AND ITS MEANINGS
}

The case of Navarre

\author{
MARÍA Jesús Rivera \\ Instituto de Estudios Sociales Avanzados (IESA-CSIC), Córdoba, España \\ mjrivera@iesa.csic.es
}

\section{RESUMEN}

El presente artículo tiene como objetivo indagar en los significados que se esconden tras el concepto paraguas de neorruralidad. El cambio residencial de la ciudad al campo es concebido aquí no sólo como un cambio de vivienda, sino como una apuesta vital en la que confluyen una serie de representaciones sociales sobre lo rural y lo urbano, sobre la vida en el pueblo y la vida en la ciudad. En el caso de quienes abandonaron Pamplona e instalaron su hogar en un pueblo de Navarra, estas representaciones y la heterogeneidad de expectativas de futuro subyacentes conforman tres tipos de neorruralidad diferentes que representan, a su vez, distintos modos de construir espacios rurales (y ruralidades) diferenciados, más o menos divergentes. A través del discurso expresado en una serie de entrevistas en profundidad, realizadas a personas que se autoidentificaban como migrantes urbano-rurales, exploramos estos tres tipos de neorruralidad y el sentido que esta apuesta residencial tuvo para sus protagonistas.

\section{Palabras Clave Adicionales}

Estrategias socio-residenciales, Idilio rural, Utopías residenciales.

\begin{abstract}
This paper examines some of the meanings that are sometimes neglected under the generic term of neorurality. From our point of view, moving one's home from town to countryside is not solely a change of house, but a life venture, bringing together social representations of the rural and the urban, of country life and the urban lifestyle. In the case of people who have moved from Pamplona (county town of Navarre, a northern region of Spain) to any rural area of Navarre, these representations, along with the broad heterogeneity of underlying reasons and expectations for the future, have shaped three different types of neo-rurality. They represent, somehow, three ways of constructing differing rural spaces (and ruralities). The paper analyses these types of neo-ruralities and the significance of the move for the migrants in the context of Navarre. To do this, we analyse the discourse expressed in diverse indepth interviews conducted with people who have identified themselves as urban-to-rural migrants.
\end{abstract}

\section{Additional KeYwords}

Socio-residential Strategies, Rural Idyll, Residential Utopias. 


\section{INTRODUCCIÓN}

A lo largo de las últimas décadas, el espacio rural ha sido testigo de profundas y diversas transformaciones encaminadas a mostrarnos una mayor variedad de funciones y necesidades a las que el campo y sus gentes debían responder. Estas transformaciones representan reflejos del modo en que en la actualidad se está reconfigurando el espacio rural y las relaciones que se establecen entre éste y la sociedad en general, así como del propio significado que adquiere lo rural en nuestros días. De hecho, puede decirse que, lejos de su rol tradicional, lo rural es hoy más que nunca un modo de confrontar la experiencia urbana, un marco a partir del cual analizar y contrastar el modelo de desarrollo económico, así como la base desde la que realizar nuevas demandas de calidad de vida (Mormont, 1998). Dichos reflejos, a su vez, llaman nuestra atención sobre lo que se ha dado a conocer como el atractivo del campo o el atractivo de la naturaleza (the lure of the countryside), que estaría en la base de los nuevos usos actuales del campo como el turismo rural, prácticas deportivas como el senderismo, la escalada y otros deportes de aventura, o el creciente número de personas que trasladan su residencia habitual de la ciudad al campo, pasando así de urbanitas a neorrurales. Esta creciente llegada de neorrurales ha sido considerada, consecuentemente, como un modo de cuestionarse la vida en la ciudad y un intento por experimentar la vida en comunidad a partir de una crítica realizada desde la experiencia de la postmodernidad, sin recurrir ni a juegos teatrales y superfluos, ni volver a tiempos pasados, sino a partir de una posición definida como (post)modernismo crítico (Halfacree, 1997)'1.

Este artículo tiene como objetivo interrogarse acerca del modo en que estos neorrurales experimentan su apuesta residencial y los significados que dicha apuesta pone en valor. El artículo se interroga también acerca de las relaciones establecidas (deseadas o no) entre la ciudad y el campo y la posible crítica (o no) de la experiencia urbana que esta apuesta residencial puede representar, así como acerca de las representaciones sociales que la animaron. Para ello, analizamos el proceso de reestructuración residencial testado en Navarra a través de una serie de entrevistas en profundidad realizadas a diversas personas que, en los últimos años, optaron por dejar Pamplona (capital de esta comunidad autónoma) como lugar de residencia e instalar su hogar familiar en un pueblo más o menos alejado de ésta² .

1 Esta posición viene a constituir una síntesis dialéctica entre el esencialismo premoderno y el postmoderno, según la cual estas tendencias reflejarían una búsqueda modernista de orden, pero relativizada por la aceptación postmoderna de las limitaciones del conocimiento.

${ }^{2}$ Estas entrevistas fueron realizadas en el contexto de la tesis doctoral de la autora. Los nombres de personas y lugares que se citan han sido anonimizados, si bien respetan el lenguaje original en el que la persona entrevistada los expresó (castellano o euskera). 
En el apartado siguiente presentamos el proceso de construcción del objeto de investigación y los presupuestos teóricos y metodológicos de partida que dieron lugar a dicho proceso. Posteriormente, exponemos los resultados del estudio, esbozando los tres modos y significados diferentes de irse a vivir al campo que las entrevistas dejaron entrever. Finalmente, indicamos algunos puntos de reflexión posibles a la luz de los datos obtenidos.

\section{CONSTRUCCIÓN DEL OBJETO DE INVESTIGACIÓN Y OBSERVACIONES METODOLÓGICAS}

Diversos estudios han puesto de manifiesto el retraso temporal con el que se ha experimentado en España el paso de una pauta de migración de carácter rural-urbano a otras de carácter urbano-rural (Fielding, 1982; Kontuly, 1998). Mientras otros países experimentaban ya un grado observable de contraurbanización, durante las décadas de los sesenta y setenta, España estaba aún inmersa en un proceso de industrialización polarizada y de rápida urbanización. Este proceso se frena a mediados de los ochenta como resultado de la crisis económica y de un giro en la economía hacia la expansión del sector terciario. Es entonces cuando comienza a evidenciarse un renacimiento de las zonas rurales (Camarero, 1993). No obstante, este cambio en la tendencia poblacional no se produce de manera radical, ni afecta de igual modo a las distintas partes del país, sino que puede convivir espacialmente con altas tasas de emigración desde las áreas rurales a las ciudades (Hoggart, 1997). Esta llegada de residentes urbanos a áreas rurales nos interroga acerca de la propia naturaleza de esta tendencia residencial, de si debe considerarse un fenómeno aislado y puntual o si, por el contrario, forma parte de un proceso más amplio de cambio y reestructuración rural. A este respecto, Hoggart y Paniagua (2001: 76) sostienen que los cambios a los que se enfrenta el mundo rural en la España actual no son fruto de un proceso de reestructuración rural, al considerar que "no ha habido una transformación fundamental de la sociedad rural", ni en términos de economía rural, ni de ecologismo, ni de la sociedad civil de dichas áreas. Según estos autores, la sociedad rural "está esperando a ser transformada, no está desorientada por una vorágine de impulsos 'extranjeros' que transforman su espíritu metafórico y reinventan sus proyectos básicos culturales, económicos, políticos y sociales" (op. cit:: 77). Desde una posición divergente, Camarero y Oliva (2002) señalan la existencia de indicios suficientes de transformación de las áreas rurales que remitirían a un proceso de reestructuración rural. Entre otros, el creciente carácter post-agrario de las áreas rurales, la creciente mercantilización del campo o la aparición de diversas y enfrentadas maneras de entender y practicar la ruralidad. Desde nuestro punto de vista, la creciente valorización del espacio rural como medio ambiente residencial ideal para un número creciente de población urbana y la consiguiente llegada de nuevos residentes a estas áreas forman parte de todo un proceso de transformación en el que la sociedad se interroga a sí misma y busca nuevas respuestas a partir de la actual configuración no sólo material, sino también ideológica y cultural (Rivera, 2007 b). Un proceso en el que 
la naturaleza y lo rural se convierten en categorías explicativas de una variedad de prácticas y preferencias sociales. Un proceso en el que la sociedad rural se aleja cada vez más de lo que fue su papel y organización tradicional.

En el caso de Navarra, este cambio de la tendencia migratoria empieza a evidenciarse, si bien de un modo aún incipiente, en la segunda mitad de los años ochenta. A partir de esta fecha, esta tendencia poblacional va adquiriendo una mayor relevancia tanto en relación con el incremento de las distancias resultantes, como en función del volumen de la población implicada y su creciente heterogeneidad. Así, junto a la migración de la clase media-alta que busca en las áreas rurales una mayor calidad del entorno residencial y un mayor distanciamiento, físico y social, de la ciudad, encontramos también la migración de jóvenes con necesidad de un espacio más barato en el que vivir o personas con escasos recursos económicos (parados, inmigrantes) que ven en los pueblos suburbanos un espacio económicamente más accesible (Camarero et al. 1998). A estos grupos, hay que añadir la llegada de personas con distintos perfiles socio-demográficos que buscan un lugar en el que llevar un estilo más natural de vida. Con todo, en menos de una década, la llegada de población urbana a las áreas rurales conforma ya un emergente paisaje social en el marco de la ruralidad en Navarra (Oliva y Camarero, 2002). Este incremento del número de personas que, con distintos grados de voluntariedad, pasan de ser urbanitas a neorrurales introduce importantes puntos de reflexión. Por un lado, nos interroga acerca de la propia naturaleza e idiosincrasia de la sociedad rural. Por otro, nos interroga también acerca del establecimiento de unas determinadas relaciones entre la ciudad y el campo, entre lo urbano y lo rural. Al mismo tiempo, llama nuestra atención sobre el papel que la dimensión "rural" tiene en la conformación de unas determinadas preferencias residenciales y en la traducción de éstas en prácticas sociales. El actual incremento de la neorruralidad se convierte, de este modo, en una tendencia que traspasa su propia expresión para dirigir nuestra mirada hacia la sociedad de la que es parte y producto.

Parece, por tanto, lógico interrogarse acerca de los motivos de esta tendencia socioresidencial. Interrogante que no se centra tanto en obtener una radiografía precisa de las condiciones que facilitan este trasvase poblacional (mejora de las infraestructuras viarias, oferta inmobiliaria, descentralización de los servicios o nuevas formas laborales) o que podían impulsarlo (deslocalización productiva, inversión inmobiliaria, etc.), como en explorar el conjunto de representaciones sociales que los protagonistas de esta tendencia residencial pudieran tener en torno a nociones como lo rural, la naturaleza, la vida de campo, el pueblo, etc. No se pretende con ello restar importancia a las mencionadas condiciones. Al contrario, consideramos que aquéllas son muy necesarias, pero no suficientes para comprender el proceso de reestructuración residencial que se observa en la actualidad. Al mismo tiempo, dichas representaciones favorecen unas determinadas prácticas residenciales en lugar de otras y éstas, a su vez, facilitan la comprensión de los distintos modos de entender y establecer la relación campo/ciudad, así como los posibles modelos de convivencia vecinal y desarrollo local que se impulsan a partir de las distintas maneras de dar sentido a la propia experiencia neorrural. 
Como ya se ha dicho, para acceder a esta información, se recurrió a la entrevista en profundidad como herramienta de análisis. La aproximación metodológica al objeto de investigación estuvo condicionada por diversos aspectos que cuestionaban la propia naturaleza del objeto estudiado: ¿qué es lo que caracteriza un espacio como rural: la actividad principal de sus gentes, el tamaño poblacional, la distancia respecto de la ciudad?, ¿dónde está el límite experiencial entre suburbanización, metropolización y contraurbanización?, ¿responden estas categorías a distintos modos de experimentar el espacio residencial o pueden solaparse 0 , incluso, perder su significado para los propios neorrurales? Con el objetivo de evitar lo más posible los efectos indeseados de una posible purificación conceptual excesiva (Halfacree, 2001), fueron las propias personas entrevistadas quienes se autodefinieron como neorrurales. Por tanto, fueron ellas quienes identificaron su nueva localidad como un espacio rural, independientemente de su distancia respecto a Pamplona, su relación funcional con ésta, la actividad mayoritaria de sus gentes, etc. Así, se intentó observar las nuevas experiencias socioresidenciales a partir de la vivencia de sus principales protagonistas y del sentido que estos les otorgaban, al margen de que formasen parte o no de categorías académicas establecidas a priori, a veces, a partir de las necesidades del investigador en lugar de responder a la naturaleza de las experiencias implicadas (Rivera, 2007a).

Finalmente, se realizaron 15 entrevistas en profundidad: 11 individuales y 4 a ambos miembros de la pareja fundacional de la unidad familiar. La duración media de las entrevistas fue de unos 80 minutos en las del primer caso y 2 horas en las del segundo. Sólo en dos de los casos el cambio residencial se había producido hacía más de 10 años. En las restantes, se había producido como máximo 5 años antes de la entrevista. Estas entrevistas se realizaron sobre una triple premisa. En primer lugar, todo cambio de residencia implica no sólo un cambio espacial, sino también un cambio en varios aspectos de la vida cotidiana, sobre todo cuando conlleva un cambio también de localidad: vecindario, relaciones sociales, movilidades, ocio, etc. Así, todo cambio residencial debe ser comprendido en términos integradores como un proyecto socio-residencial, una inversión socio-biográfica en la que se entremezclan distintos tipos de elementos: materiales, económicos y simbólicos (Bourdieu, 2003). En segundo lugar, detrás del abandono de la ciudad como lugar del hogar familiar y su traslado a una localidad de carácter rural se produce un triple cambio: espacio doméstico (vivienda), entorno social inmediato (vecindario de la nueva localidad) y entorno físico y medioambiental (espacio físico del pueblo y alrededores). Por último, todo proceso de migración es un acontecimiento cultural que refleja la personalidad de los migrantes, sus lealtades, valores y compromisos (Fielding, 1992), a la vez que un acontecimiento biográfico que adquiere todo su sentido, no cuando es observado aisladamente, sino cuando es puesto en relación con la propia biografía de sus protagonistas (Halfacree y Boyle, 1993). Por ello, a través de las entrevistas se exploraron diversos aspectos relacionados, no sólo con las representaciones sociales asociadas a su preferencia residencial, sino también con su biografía residencial pasada, sus planes de futuro, motivos del cambio residencial, elección del lugar definitivo, participación en la vida social y política de la localidad, 
formación, trabajo, aficiones, prácticas de ocio y consumo, etc. De este modo, entre la narración de su experiencia cotidiana fueron aflorando distintos aspectos como los viejos sueños, los recuerdos, las frustraciones o las aspiraciones de los protagonistas de las nuevas estrategias neorrurales.

\section{APUESTAS SOCIO-RESIDENCIALES Y VUELTA AL CAMPO}

Una primera lectura del discurso de los entrevistados mostró como todas las personas entrevistadas compartían una representación social del pueblo como un ambiente físico y social más propicio que la ciudad para el establecimiento de unas relaciones humanas más francas, honestas, basadas en la confianza y conocimiento mutuos. Unas relaciones asociadas a la experiencia de vivir en comunidad, del espíritu comunitario. Esta primera lectura mostró también como las personas entrevistadas compartían además una estética basada en elementos propios de una inversión de valores característica del neoarcaismo urbano (Morin, 1973). Fuego bajo, vigas de madera a la vista, elementos decorativos de cerámica o plantas forman todo un complejo simbólico que permite a nuestros entrevistados enraizarse no en una moda pasajera, sino en un tiempo pasado, en una dimensión de pertenencia e identidad. Esta primera lectura, superficial por necesidad, arrojaba una imagen excesivamente homogénea de los neorrurales, que podría hacer pensar que estos habían elaborado sus preferencias residenciales a partir de una base estética común y de un conjunto de representaciones sociales en el que los elementos compartidos serían más relevantes que las diferencias de matices que pudiese haber entre ellos.

No obstante, una mirada más detallada al discurso de los entrevistados desvelaba las importantes diferencias entre estos. Éstas asomaron al poner en relación las representaciones sociales mantenidas y el papel que el cambio residencial supuso en el proyecto vital de la unidad doméstica. A partir de este momento, las diferentes biografías y las diferentes expectativas que los neorrurales habían tenido respecto a su apuesta socio-residencial, tanto en su dimensión física como social, fueron dibujando distintos modos de entender y practicar la neorruralidad. Distintos modos de comprender lo rural, de establecer la relación campo/ciudad y de participar en la vida cotidiana de la nueva localidad. Esto es, distintas maneras de apropiarse del espacio rural a través de su uso residencial. A la hora de caracterizar estas diferencias, se tuvieron en cuenta tanto elementos simbólicos como, por ejemplo, las representaciones sociales mantenidas en torno a conceptos como la naturaleza 0 el pueblo como las prácticas sociales que las personas entrevistadas mantenían respecto al consumo, la movilidad cotidiana, el ocio, etc.

Hay que destacar una primera línea divisoria fundamental entre aquellos que consideran que se vieron obligados a trasladar el hogar familiar de la ciudad al campo por distintos motivos y aquellos que interpretan su traslado residencial como el resultado de una decisión libremente adoptada, aún a pesar de las posibles limitaciones que pudieron afectar su elección final (fundamentalmente de tipo económico). Mientras en 
el primer caso podemos considerar que la elección residencial responde a un proyecto distópico fruto de la imposibilidad de llevar acabo el proyecto residencial deseado como primera opción, en el segundo caso, la apuesta residencial es el resultado de un proyecto utópico a través del cual las personas entrevistadas intentan dar respuesta a sus propias preferencias y deseos. No obstante, como se verá más adelante, a pesar de compartir este componente utópico de partida, en este segundo grupo se observan dos maneras diferentes de dar forma a dichos deseos en función del grado de implicación con la que los nuevos residentes rurales se embarcan en la vida de la localidad.

Así las cosas, a través del discurso de los entrevistados, se perfilaron tres maneras de irse a vivir al campo. Tres expresiones de la neorruralidad que no sólo muestran distintas relaciones entre las representaciones sociales compartidas, sino que van a dar como resultado distintos espacios rurales y distintas dinámicas de desarrollo (Rivera y Mormont, 2006).

\section{DISTOPÍA PRAGMÁTICA: ESPACIOS PERI-URBANOS, ESPACIOS DE ADAPTACIÓN, MOVILIDAD Y PROXIMIDAD. EL DOMINIO DEL HOGAR}

En este primer caso, como hemos adelantado, la estrategia residencial finalmente adoptada es considerada por sus propios protagonistas como la mejor solución posible ante necesidades y limitaciones de distinto tipo experimentadas en un momento concreto. Se construye así una legitimación guiada esencialmente por un pragmatismo residencial en la que, si bien se da cabida a antiguos deseos, son las limitaciones de espacio, la necesidad de cercanía a la ciudad o las restricciones económicas las que la conforman primordialmente. Se trata de una estrategia que se despliega en el momento fundacional de la unidad doméstica o en un momento en el que se produce un importante cambio en la vida de ésta. Una estrategia que refleja de manera nítida la disyuntiva entre el hábitat deseado y las limitaciones de la unidad doméstica:

"Entonces de repente se nos planteó el problema de que tenía que venir a vivir con nosotros mi suegra y no había sitio. [...] Entonces empezamos a buscar pues pisos. A mi marido siempre le había hecho ilusión tener una casa. Yo le decía que si era lejos de Pamplona yo no quería. [...] Necesitaba cinco habitaciones y no es muy fácil [encontrar un piso de esas características en Pamplona]" (mujer, 53 años, ama de casa).

Esta estrategia residencial se extiende sobre lo que podríamos caracterizar como pueblos peri-urbanos, dado que la cercanía a la ciudad era uno de los requisitos de sus protagonistas, quienes se desplazan a Pamplona a diario tanto por motivos laborales como de ocio, compras, relaciones sociales, familiares, etc. De este modo, estos destinos residenciales permiten dar respuesta a una diversidad de necesidades, desde un mayor espacio físico económicamente más asequible que en la ciudad, hasta un distanciamiento no sólo físico, sino también simbólico de la ciudad, o el acceso a una 
vivienda y un entorno rural más baratos que en áreas más remotas ${ }^{3}$.

La movilidad cotidiana hacia y desde la ciudad se realizará a expensas del automóvil particular en detrimento de los posibles medios de transporte público. El recurso a la automovilidad, al igual que sucederá en el siguiente caso de neorruralidad analizado, se convierte en una condición imprescindible para el éxito de esta estrategia residencial. Un uso por tanto generalizado del automóvil que permite un desplazamiento constante entre diversos espacios y tiempos. Esta estrategia está, por tanto, vinculada al constante tránsito entre la ciudad y el nuevo lugar de residencia. Y, como también sucederá en la siguiente estrategia, los protagonistas de esta distopía pragmática desarrollan en la ciudad sus actividades principales tanto laborales como relacionales. De hecho, el único cambio importante introducido en la vida de sus protagonistas es el lugar en el que estos se recogen al final del día, manteniendo prácticamente inalteradas las actividades cotidianas que realizaban antes de trasladarse al nuevo lugar ${ }^{4}$. En este sentido, la elección final del lugar de residencia se basó en valoraciones pragmáticas, intentando adecuar las nuevas necesidades residenciales, las posibilidades económicas y la posibilidad de seguir realizando su vida en la ciudad.

Pero volviendo a las preguntas que orientaron nuestra investigación, ¿cómo experimentan estos neorrurales su nueva vida?, ¿qué elementos contribuyen a construir o dar sentido a esta experiencia? Como consecuencia lógica del carácter pragmático y de adaptación que tuvo en su día el cambio residencial, este perfil de neorrurales legitima su decisión esencialmente en función del mayor espacio físico disponible y del mayor grado de independencia que éste les permite respecto al vecindario ${ }^{5}$. Una independencia que podemos interpretar tanto como un modo de evitar malas relaciones, como el logro de una mayor libertad de actuación dado el menor control visual de los vecinos.

"[...] que si te levantas por la mañana y sales en pijama a ver el sol ... pues sales en pijama a ver el sol porque estás en tu casa ¿no?" ( mujer, 28 años, desempleada).

\footnotetext{
${ }^{3}$ Si bien podemos encontrar varios municipios compuestos por una sola entidad poblacional, el hábitat de la comarca de Pamplona se caracteriza por una diversidad de pueblos y aldeas agrupados en diversos municipios. Esta diversidad ha permitido la coexistencia de diferentes tipos de recién llegados en espacios muy cercanos. Mientras algunos pueblos se han convertido en el destino de una población de carácter obrero, fundamentalmente jóvenes e inmigrantes en busca de suelo más barato, otros pueblos son el destino ideal para una población de clase media-alta que busca en dichos espacios un distanciamiento social de la ciudad y la recreación residencial de utopías concretas en nuevas urbanizaciones (vid. Morin, 1968).

${ }^{4}$ Las compras son quizás la actividad que más se modifica. Aun así, las personas entrevistadas refieren aprovechar los desplazamientos a la ciudad para hacer las compras o realizarlas en un hipermercado. De este modo, las compras en los establecimientos locales, cuando los hay, son más esporádicas y de pequeño volumen que regulares y de gran volumen. En algunos casos, también se adquieren directamente a particulares locales ciertos productos como la leche o los huevos.

${ }^{5}$ Es importante resaltar en este sentido que el cambio de residencia de la ciudad al campo conlleva, de manera generalizada, el paso de vivir en un piso o apartamento a hacerlo en una vivienda individual.
} 
Como todo cambio residencial, especialmente cuando conlleva la compra del inmueble, supone no sólo una importante inversión económica y patrimonial, sino también emocional. Ésta es especialmente apreciable cuando observamos el proceso de transformación de la nueva vivienda en hogar. Este proceso implica una personalización del hogar no ya sólo en términos de las necesidades espaciales de la unidad doméstica, sino también en términos de la adecuación a la propia identidad de sus nuevos moradores, dotándose así de una potente carga simbólica y convirtiéndose en un lugar significativo para el devenir de la unidad doméstica.

"Y ver como transformas una vivienda, eso es una sensación muy bonita. $Y$ la transformas en muchos casos con lo que haces tú [...] Pero ver cómo se transforma la casa, ver..." (varón, 36 años, trabajador autónomo en nuevas tecnologías).

Si la vivienda y la autonomía que ésta les permite, así como el mayor espacio disponible constituyen los principales aspectos que dan sentido a esta estrategia residencial, el pueblo y su entorno apenas fueron considerados a la hora de definir su apuesta residencial, algo por otra parte coherente con el proyecto residencial y vital de estos neorrurales. Esta aparente falta de interés por su entorno físico y social más inmediato es entendible dado que tanto el hecho de abandonar la ciudad como el lugar finalmente escogido no fueron el resultado de la elaboración progresiva de un deseo, sino el resultado de una necesaria adaptación a nuevas circunstancias y determinadas limitaciones. La escasa referencia espontánea durante las entrevistas se hace aún más comprensible si consideramos que, como ya hemos avanzado, la inmensa mayoría de las actividades cotidianas de este perfil de neorrurales permanecen vinculadas a la ciudad. Consecuentemente, la potencialidad de la nueva localidad de residencia como espacio de sociabilidad y relación es apenas remarcado por las personas entrevistadas. Encontramos, por tanto, una fractura con la idea primera que vinculaba este fenómeno residencial a un énfasis de su dimensión rural y a la búsqueda de un sentimiento de comunidad. Como se verá, este hecho marca una clara diferenciación con las otras dos apuestas residenciales observadas.

A pesar de que el discurso expresado por todas las personas entrevistadas deja entrever un cierto grado de congruencia entre la dimensión rural de esta preferencia residencial y una base compartida respecto a su imaginario sobre la naturaleza, esta misma imagen de la naturaleza puede responder a distintas valoraciones. En el caso de los neorrurales de distopía pragmática, estos valoran la naturaleza (el medio ambiente más inmediato) en función de su potencial como recurso de esparcimiento. De este modo, las personas entrevistadas adoptan con respecto a la naturaleza una posición fundamentalmente instrumental. Se sitúan a sí mismos como observadores externos que pueden apropiarse de la naturaleza a través de distintas prácticas como los paseos o la recreación visual (vistas). Así, más que sujetos que buscan hacerse uno con la naturaleza, este tipo de neorrurales se sitúa en una posición externa de observador y usuario de un recurso que le viene dado. 
"Tienes el monte cercano, que es también bonito para poder andar. Hacia la zona de Pueblocercano también hay unos paseos muy bonitos por el monte. Yo lo que destacaría un poco es, para mi gusto, el monte, el Altumendi. Le da un entorno bonito ¿eh? O sea, tiene... bueno, pues esa... Y es un sitio agradable de pasear y... hay animales, tienes caballos" (mujer, 42 años, administrativa en negocio familiar).

Por lo dicho hasta el momento, el proyecto que subyace a esta estrategia residencial es un proyecto esencialmente pragmático que busca la mejor adaptación posible a una situación dada. El discurso de sus protagonistas dibuja un imaginario en el que la dimensión pueblo (entorno social inmediato) en tanto que espacio privilegiado de unas determinadas pautas de relación social apenas está presente. Un discurso que convierte a la naturaleza en un recurso a su disposición, para su uso y disfrute, a través de diferentes prácticas espaciales y experiencias estéticas. Un discurso que prioriza claramente la dimensión hogar respecto a las otras en la narrativa de su autolegitimación. Pero más allá de este imaginario, ¿representa esta apuesta residencial un cierto grado de crítica de la experiencia urbana en la actualidad? A la vista del análisis de las entrevistas, resulta difícil considerar esta estrategia residencial como una respuesta a un malestar producido por la experiencia urbana, como una crítica más o menos explícita del actual modo de vida y de la calidad de vida residencial que ofrece la ciudad. Si bien se aprecian elementos concernientes al tamaño de las viviendas o su carestía, las personas entrevistadas no elaboran un discurso crítico, más allá de estos aspectos, que aborde el propio estilo de vida. Es por ello que esta estrategia refleja más un modo de adaptación a unas circunstancias determinadas que la búsqueda de un modo de vida alternativo, como respuesta a un proceso crítico reflexivo.

\section{Utopía DE REFUGIO: SALVACIÓN INDIVIDUAL, MOVILIDAD Y FLEXIBILIDAD ESPACIAL. EL DOMINIO DE LA COMUNIDAD}

Frente a lo que sucedía en el caso anterior, en este segundo proyecto socio-residencial, el discurso expresado en las entrevistas deja traslucir un cierto grado de crítica a la actual experiencia de la vida urbana. A lo largo de las entrevistas se va hilvanando una imagen de la ciudad en la que la promesa de desarrollo humano ha dejado paso a una ciudad que dificulta las relaciones sociales y en la que las relaciones vecinales, caracterizadas ahora por el desconocimiento mutuo y la falta de confianza, se ven mayoritariamente reducidas a intercambios y encuentros superficiales. Pero la crítica del modo de vida urbano no se circunscribe a las dinámicas relacionales, sino que alcanza también al estilo de vida impuesto por la ciudad. Un modo de vida en el que el tráfico, los atascos y las prisas de la gente confluyen en un estrés generalizado que alcanza al conjunto de sus habitantes y cuestiona la imagen de la utopía urbana de la modernidad.

"Me parece una concentración de todo. De coches, de gente, de que todo el mundo va corriendo y de que ... pues no conoces a nadie" (mujer, 27 años, servicio doméstico). 
Ante esta vivencia de la ciudad los neorrurales intentan, a través de su apuesta residencial, crearse fuera de la ciudad un refugio a medida en el cual poder distanciarse de ésta y descansar al final del día del estrés cotidiano que les genera. De este modo, los protagonistas de esta estrategia residencial la legitiman no ya como el resultado de su necesaria adaptación a unas circunstancias determinadas, sino como la consecución de una preferencia residencial, como la satisfacción de un deseo preexistente.

"Hombre, siempre estás pensando ¿no? pues que te gustaría vivir en un pueblo y que un día de estos tenemos que meternos en una casa" (varón, 30 años, trabajador industrial).

El hecho de que esta estrategia residencial responda al deseo de sus protagonistas hace que la elección final del nuevo lugar sea más selectiva que en el caso anterior y adquiera un mayor peso a lo largo de las entrevistas. Es destacable como en esta estrategia neorrural de refugio, la biografía residencial de sus protagonistas puede marcar definitivamente la elección de la nueva localidad. Esto es especialmente observable en los casos en los que la familia de alguno de los miembros de la pareja es originaria de un pueblo. En estos casos, los recuerdos de la infancia, adolescencia y juventud (especialmente fines de semana y periodos vacacionales) se convierten en un argumento fundamental de la decisión final, ya que a menudo se tratará de instalar el nuevo hogar en el pueblo o zona de la que la familia es oriunda.

"Y coincidió que esta zona... bueno, los padres de Jon... El padre, que murió, era de Aldeavecina, del pueblo de al lado, y la madre de Pueblocercano. Y, entonces, ellos de pequeños habían tenido alquilada una casa en Aldeavecina y él había venido pues muchos veranos siendo crío. Bueno, crío y adolescente. Había venido mucho aquí. Entonces a él le hacía más... Quería comprar en Aldeavecina" (mujer, 37 años, profesora de instituto).

En los casos en los que este juego de la memoria no actúa, la elección final del lugar -y la apuesta de futuro que supone- es el resultado de la consideración de una diversidad de elementos en los que los deseos iniciales van ajustándose a las posibilidades reales en función de las limitaciones de la unidad doméstica, principalmente en términos económicos y de distancia respecto a Pamplona.

"Pero al principio sí que decíamos: una que esté cerca. ¡Claro! Y tú dices: la distancia ¿qué? ¿a veinte minutos? ¿media hora? ... Que tuviera posada, que tuviera niños... Que habría así como ambiente para un futuro. Pero luego ves que eso es ... [económicamente inviable]" (mujer, 31 años, comercio) ${ }^{6}$.

Esta estrategia residencial está, por tanto, vinculada a un deseo expreso de salir de la ciudad, si bien al igual que sucedía en el caso de la distopía pragmática los protagonistas

\footnotetext{
${ }^{6}$ Como se verá, en el caso de los protagonistas de la apuesta residencial de arraigo será, precisamente, esta cercanía de lo que buscan distanciarse.
} 
de la utopía de refugio mantienen en la ciudad sus principales prácticas cotidianas: trabajo, amistades, compras, etc. Pero, al contrario de lo que sucedía en el primer caso, ahora el discurso de las personas entrevistadas expresa un grado manifiesto de crítica hacia la experiencia urbana. Es precisamente en respuesta a esta dimensión crítica que los protagonistas de esta estrategia residencial legitiman su apuesta socio-residencial. Es decir, su estrategia residencial implica para ellos un distanciamiento voluntario de la ciudad tanto físico como simbólico. No obstante, el malestar generado por la ciudad, sus ritmos y el estilo de vida que genera no implica un deseo de ruptura con la ciudad, sino más bien la creación de un espacio privado e íntimo en el que refugiarse y regenerarse al final del día.

"Y luego, los problemas que puedas traer del trabajo, de... pues el agobio, el cansancio, vienes aquí y desconectas más fácil de todo eso. [...] Y te vas a dar una vuelta por el campo, a respirar aire, a oxigenarte." (mujer, 37 años, profesora de instituto).

La necesidad de compaginar la vida laboral en la ciudad y el retiro en la localidad rural conlleva que esta estrategia residencial se extienda sobre áreas más alejadas de la ciudad que las que encontrábamos en el caso de la distopía pragmática, pero no lo suficiente como para impedir los continuos desplazamientos diarios entre la ciudad y el pueblo. Y al igual que sucedía en el caso anterior, estos desplazamientos entre ambos espacios se realizan gracias al uso del automóvil particular, convirtiéndose de nuevo la automovilidad en una condición imprescindible a la hora de llevar con éxito a la práctica esta apuesta socio-residencial.

Pero volviendo al discurso expresado en las entrevistas, éste refleja de un modo más explícito que en la anterior apuesta residencial una serie de representaciones sociales más cercanas a aquéllas del idilio rural y la arcadia pastoril, que nos dibujan el hábitat rural como un espacio en el que las pautas de convivencia están regidas por la franqueza, la tranquilidad y la confianza mutua y el ritmo de vida de sus gentes responde a los propios ritmos de la naturaleza. Es la representación de esta atmósfera utópica la que alienta los proyectos socio-residenciales de estos neorrurales.

Ante el malestar, estrés, etc. generado por el ritmo de vida de la ciudad, los protagonistas de la utopía de refugio van a crearse un espacio propio donde resguardarse y encontrar su pequeño refugio particular al final del día, un espacio de identidad y recogimiento en el que recuperarse de los problemas generados en la ciudad. Este refugio se va a construir esencialmente sobre dos dimensiones: la casa y el pueblo. Respecto a la primera, ésta se erige en un elemento esencial para comprender la apuesta socio-residencial hecha por estos neorrurales. De modo similar a como sucedía en la neorruralidad distópica, la casa es valorada por la mayor calidad de vida que les proporciona respecto al anterior piso en la ciudad, tanto en términos de mayor espacio físico como de independencia respecto a los vecinos más próximos. No obstante, junto a estas valoraciones, que podríamos calificar de pragmáticas, en la utopía de refugio se aprecia una valoración del espacio doméstico más compleja al poner en relación 
la calidad de vida que proporciona con el propio desarrollo personal y la posibilidad de llevar un estilo de vida más acorde con las preferencias personales. La relación que se establece entonces con el espacio residencial (al menos a nivel ideacional) aparece más claramente mediatizada con procesos de identidad y autoexpresión.

"En nuestro caso, pasar de un piso a una casa a vivir siempre será mayor calidad de vida ¿no? Siempre tendrás más espacio para vivir un poco de la manera que tú quieras" (mujer, 39 años, maestra de escuela).

La importancia significativa que adquiere el nuevo hogar se refleja de nuevo en la inversión afectiva y temporal que conlleva el proceso de personalización de la casa, su pasaje de alojamiento a hogar. Un proceso que está vinculado a la recreación de una estética neoarcaica como un modo de dar continuidad entre pasado y presente, un modo de rodearnos de objetos y elementos como paredes de piedra, vigas de madera, etc. no sólo por su estética determinada, sino por su carácter evocador de un pasado idiosincrásico.

"[Nos atrajo] pues toda la casa. Que tenía muchas posibilidades y era muy bonita. De estructura de piedra... Mira que piedra más guapa tiene. Ésta la sacó éste [su pareja], que estaba tapada ¿no?" (mujer, 45 años, comercio de marroquinería).

En este proceso de creación del hogar y refugio, los protagonistas de esta estrategia socio-residencial intentan construir pequeñas recreaciones de naturaleza en casa a través del jardín y/o huerto doméstico. Estos espacios representan pequeños retazos de naturalezas privadas, domésticas, cargadas de un importante componente afectivo y valoradas tanto como elemento de recreación estética y ociosa, como en función de las posibilidades que ofrece a la hora de cultivar los propios alimentos.

"Tenemos plantado un nogalito ¿no? Ya debajo, te pones una hamaca, te pones a leer ahí. Eso es una gozada. Te sacas la merienda. Te sacas el té. Hoy porque ha hecho un día gris y eso pero te vas a tomar el té abajo y eso es una gozada (...) Porque eso de ir abajo y cogerme la lechugica, sin pesticidas ni leches. 0 sea, que haces una alimentación mucho más sana. Estas comiendo de lo tuyo. De lo que has puesto tú y estás viendo crecer" (mujer, 45 años, comercio de marroquinería).

Respecto a la importancia de la dimensión pueblo a la hora de la creación de un refugio físico y simbólico, hay que decir que éste representa el entorno social más inmediato de la unidad doméstica. Como ya hemos adelantado, este constructo nos muestra un imaginario vinculado a un modo de vida prototípico de pueblo en el que su menor número de habitantes y su entorno hacen de él el espacio idóneo para establecer unas relaciones vecinales basadas en la espontaneidad, el conocimiento y confianza mutua, por oposición al tipo de relaciones impuesta por el propio ritmo y dinámica de la ciudad. Unas relaciones de convivencia que nos acercan al espíritu de la comunidad ideal, frente a la anomia social con la que se representa la ciudad. 
"Mira, una de las cosas que más me gusta del pueblo es la relación que tienes con la gente ¿no? Es como más familiar, es otro trato" (varón, 30 años, trabjador industrial).

Este clima de confianza y conocimiento de los vecinos, junto a la consiguiente mayor percepción de seguridad, convierte a la localidad rural en el tipo de hábitat, físico y social, idóneo para la crianza de los hijos. Ésta se beneficia no sólo de esta atmósfera vecinal, sino también de los beneficios derivados del contacto directo con la naturaleza.

"Le ves como está, como disfruta abajo en la calle, en la huerta, la relación que tiene, pues que conoce las cosas de la huerta, los animales... la relación esa. 0 el... el cariño ¿no? que se te mete sin... [...] Nosotros, cuando nos planteamos tener un crío, pues una de las cosas... jo... que nos gustaba era ésa ¿no? Que él pudiera pasar su... su infancia en un medio asi" (mujer, 37 años, profesora de instituto).

Al dirigir nuestra atención a la dimensión naturaleza en el discurso de los neorrurales de la utopía de refugio, vemos que estos comparten con los protagonistas de la anterior apuesta residencial su representación como entorno residencial y su valor en tanto que elemento de recreación estética. No obstante, su narrativa sobre este elemento se presenta más elaborada que en el caso anterior. Así, junto a la mencionada recreación privada de pequeñas naturalezas, este tipo de neorrurales valora esta dimensión en función de su valor estético y las posibilidades de recreación que les proporciona: paseos, momentos de contemplación, etc. Sin embargo, a pesar de situarse (al igual que sucedía en el caso anterior) en una posición de exterioridad, de un observador/ espectador, los protagonistas de esta apuesta socio-residencial comienzan a valorar el potencial regenerador de la dimensión naturaleza, su capacidad para hacerles olvidar los problemas que traen de la ciudad. La sensación que produce llegar al pueblo, salir a la calle, ver los animales y la naturaleza puede resumirse en la máxima:

"Es simplemente la tranquilidad, el estar en la calle" (mujer, 27 años, servicio doméstico).

\section{UtOPíA dE ARRAIGO: CAMBIO DE VIDA, ARRAIGO Y DISTANCIAMIENTO. EL DOMINIO DE LA NATURALEZA}

A partir del discurso expresado en las entrevistas, se observa un tercer grupo de neorrurales, esto es, una tercera manera de poner en práctica la vuelta al campo, de experimentar la vida cotidiana en relación con la nueva localidad, una tercera manera de concebir qué es el campo y qué es vivir en un pueblo. Como hemos avanzado, este tercer grupo participa, al igual que en el caso anterior, de un proyecto utópico. Es decir, sus protagonistas vinculan claramente su estrategia residencial con la consecución de un deseo elaborado en un espacio más o menos dilatado en el tiempo y no con la adaptación más factible ante una serie de determinadas necesidades y constricciones. No obstante, esta estrategia residencial va también a diferenciarse de manera meridiana 
de la apuesta de refugio que venimos de explicar en un aspecto fundamental, ya que va a representar no la búsqueda de un refugio, sino un intento por encontrar un nuevo centro de arraigo y un sentimiento de pertenencia. Ahora, el distanciamiento de la ciudad no sólo conlleva una lejanía física y simbólica. Más que una necesidad de distanciamiento espacial y simbólico, esta estrategia refleja una necesidad más compleja y vital, en la que el distanciamiento supone al mismo tiempo una nueva experiencia cotidiana, un cambio radical en la vida de los neorrurales.

En el primer tipo de neorruralidad, la ciudad era para sus protagonistas el espacio cotidiano del trabajo, servicio, ocio, relaciones sociales, etc. y la nueva localidad el mero emplazamiento de la vivienda. En el segundo tipo analizado, la ciudad va restringiéndose poco a poco al espacio del trabajo y sociabilidad, al tiempo que se convierte en un importante motivo de estrés y malestar. El nuevo emplazamiento de la vivienda representa por tanto el espacio de recogimiento y refugio que nos permite desvincularnos de la ciudad y regenerarnos del desgaste producido por ésta. En la utopía de arraigo, se ahonda en esta representación de la ciudad como un espacio vivo con sus propios ritmos que niega a sus habitantes la posibilidad de vivir de acuerdo a sus tiempos y necesidades particulares.

"En la ciudad no puedes vivir según tu propio ritmo. La ciudad te impone el ritmo" (mujer, 31 años, docente en educación no formal).

Esto, junto a la percepción de algunos de los problemas generados por la propia ciudad (tráfico, polución, ruido...), provoca que la ciudad sea percibida por los protagonistas de este tipo de neorruralidad como un espacio del que necesitan salir para llevar una vida más acorde con su propia naturaleza y sus planes de futuro. Esta experiencia de la vida urbana hace que el deseo de irse a vivir al campo se haya elaborado en el tiempo y se vincule a la consecución de un profundo cambio del modo de vida.

"Llevábamos un largo tiempo con la idea ¿no? Jo, comprar una casa... Siempre lo habíamos hablado en el piso en el que vivíamos juntas. O sea, comprar una casa en un pueblo. La historia de siempre que crees que nunca se cumplirá" (mujer, 31 años, docente en eduación no formal).

Dado que el deseo va conformándose a lo largo del tiempo, la elección final de la localidad de destino se convierte en un aspecto que no se deja al azar, sino que el proceso de búsqueda adquiere un carácter más selectivo, generalmente basado en una elección previa de la zona, en la que las preferencias estéticas y el conocimiento tienen un gran peso.

"Siempre que veníamos al monte por aquí, algún fin de semana o lo que sea, por aquí o por cualquier zona de Estamontaña, siempre ... 'Jo, algún día una por aquí para fin de semana... Tenemos que acabar cogiendo alguna bordica, arreglarla, ...' [decía el marido]" (mujer, 37 años, autónoma del sector servicios). 
Así, poco a poco, junto al deseo expreso de abandonar la ciudad y el modo de vida urbano y de unas preferencias residenciales determinadas, los protagonistas de esta estrategia residencial consideran que su necesidad de distanciamiento de la ciudad no puede satisfacerse a través del mero traslado del hogar a una localidad en la que refugiarse al final del día, sino que éste debe ir acompañado de una transformación en el propio estilo de vida. Este cambio se traduce en un abandono del trabajo en la ciudad y el inicio de una nueva actividad laboral en la localidad o sus cercanías, ya sea en la misma en la que trabajaban anteriormente 0 en una diferente; ya sea una actividad directamente relacionada con las actividades tradicionales del medio rural -las menos- 0 una actividad vinculada al sector servicios (apertura de un restaurante, una peluquería, etc) -las más. De este modo, esta apuesta socio-residencial introduce una importante diferencia con las otras dos apuestas analizadas, esto es, el commuting diario hacia y desde la ciudad deja de ser una experiencia cotidiana. Este deseo expreso de menor movilidad espacial viene asociado a una diferente valoración del automóvil y su uso. Mientras que en las apuestas anteriores su uso era una condición para el éxito del proyecto de vida, en el caso de la utopía de arraigo este menor uso es considerado como un signo de su mayor calidad de vida, al tiempo que representa un modo de cuestionar la vida en la ciudad.

"Pero también es una gozada. No tienes que andar con el coche. Vas [a llevar a los hijos a la escuela], vienes [a casa], estás con la gente..." (mujer, 37 años, autónoma del sector servicios).

Este deseo expreso de distanciamiento de la ciudad y su ritmo de vida, así como la estrategia laboral basada en la vecindad, propician que esta apuesta socio-residencial se extienda sobre áreas rurales más remotas respecto de la ciudad que las que encontrábamos en los casos precedentes. Pero esta apuesta socio-residencial conlleva mucho más que un simple cambio de residencia y trabajo. Sus protagonistas buscan una integración en la vida de la localidad a través de su participación en un mayor número de actividades que las referidas por los protagonistas de las apuestas anteriores: actividades socio-culturales, compras, vida política, etc ${ }^{7}$. A través de esta mayor participación en la vida de la nueva localidad, los neorrurales de arraigo pasan a formar parte de una nueva red de relaciones sociales, a la vez que van a intentar intervenir de un modo explícito en el futuro desarrollo de su nueva localidad. Un desarrollo que ahora está íntima y directamente ligado a su propio desarrollo, a su nuevo proyecto de vida.

Frente al escaso poder estructurante de la dimensión vivienda en el discurso expresado por los protagonistas de la utopía de arraigo (más allá de su clara vinculación con la estética neoarcaica y el deseo de recuperar elementos considerados tradicionales),

\footnotetext{
${ }^{7}$ Este mayor compromiso activo con la vida de la localidad no supone a priori una mayor integración de los neorrurales en su nueva población de destino.
} 
son las dimensiones pueblo y naturaleza las que cobran una mayor relevancia como argumento legitimador de su apuesta socio-residencial. Respecto al primero, podemos decir que frente a lo que sucedía en las apuestas precedentes, éste ya no representa sólo un entorno diferente en el que vivir, sino que representa también un medio y un modo de vida diferente al que llevaban en su anterior vida en la ciudad. Un medio de vida en tanto en cuanto la apuesta socio-residencial está vinculada a un cambio también en el terreno laboral. Y un modo de vida en tanto en cuanto las personas entrevistadas vinculan imaginariamente el espacio rural, sus gentes y sus dinámicas a un determinado estilo de vida.

"Cuando fui a vivir al pueblo fui para vivir como yo creía que se tiene que vivir ¿no? No para dormir. Si no, no hay mucha diferencia entre vivir en un pueblo y vivir en Pamplona" (mujer, 29 años, técnica en un sindicato agrario).

Como sucedía en el caso de la utopía de refugio, en esta construcción imaginaria del pueblo en tanto que hábitat físico y social, la crianza de los hijos se convierte en un elemento esencial a la hora de legitimar esta apuesta socio-residencial y de dar un significado preciso a la mayor calidad de vida atribuida al medio rural en comparación con el urbano. La mayor percepción de seguridad vinculada al conocimiento de los vecinos, el contacto directo con la naturaleza o el propio clima propician, desde el punto de vista de estos neorrurales, una crianza más sana y feliz que la de la ciudad.

"Los críos del pueblo generalmente los ves como con coloricos, tal, sanos... Yo creo, no sé sí es por el aire, porque están acostumbrados al frío..." (varón, 35 años, autónomo sector servicios).

El pueblo representa, por tanto, un modo de vida, un lugar adecuado para la reproducción doméstica y un espacio de sociabilidad en el que construirse un nuevo centro de arraigo y pertenencia. Esta construcción pasa por la participación activa en las distintas redes sociales que atraviesan los distintos aspectos de la vida de la localidad. No obstante, la consecución y éxito de esta participación no va a depender exclusivamente de los esfuerzos de estos neorrurales, sino que viene también condicionada por la capacidad de la población local para aceptar las diferencias introducidas por estos. Consecuentemente, de manera similar a lo reflejado en la apuesta precedente, la gran inversión afectiva que esta apuesta socio-residencial conlleva no siempre finaliza con éxito o de la manera que las personas entrevistadas esperaban y, en muchas ocasiones, los neorrurales acaban relacionándose entre sí más que con la población local. La constatación de la dificultad -a veces fracaso- de este intento de aceptación e integración en la vida de la localidad supone al mismo tiempo el cuestionamiento de las propias diferencias.

“(...) algunas veces [las relaciones vecinales] son rígidas y [los vecinos de la localidad] no entienden que tú seas tan directa. (...) También se te hacen difíciles algunas dinámicas ¿no? 
Pues... el tener que callar muchas cosas ¿no? Igual dices algo y la gente se sorprende. Lo que es normal en Iruñea aquí no lo es tanto ¿no? Entonces a mí, por lo menos, me ha costado. Me ha costado seguir esa dinámica sin perder mi identidad" (mujer, 31 años, servicio doméstico).

En la búsqueda del nuevo modo de vida que esta apuesta socio-residencial representa, la naturaleza se constituye en otro de sus elementos legitimadores por parte de las personas entrevistadas. Como hemos visto, esta apuesta responde a un deseo expreso por alejarse de la ciudad, sus ritmos y su experiencia cotidiana. El modo de vida que los protagonistas de la utopía de arraigo pretenden abrazar pasa necesariamente por mantener una relación determinada también con la naturaleza. Si bien estos neorrurales comparten con los anteriores una representación de la naturaleza como un potencial de capacidad regeneradora, a lo largo de las entrevistas vemos como los neorrurales de arraigo se alejan de la posición de observador externo de la naturaleza que se apropia de ésta a través de diversas prácticas para acercarse a una posición de unicidad con ella. Dicho de otro modo, el anterior carácter instrumental que dominaba la relación sujeto/naturaleza cede ante una relación en la que predomina un acercamiento más existencial entre ambos. La persona ya no es tanto un elemento externo como una parte integrante de aquella. Esta posición refleja, a su vez, una determinada experiencia de la vida moderna urbana y el intento por embarcarse en una experiencia distinta, por acoplarse a los ritmos de la naturaleza, situándose en una posición de interioridad respecto a ésta, de la cual se siente parte y con la que comparte su lento paso del tiempo, su evolución sin fin (vid. Macnaughten y Urry, 1998).

"Te despiertas a la mañana y ves el bosque. Ves como pasan las estaciones ¿no?" (mujer, 31 años, servicio doméstico).

\section{Conclusión: LA NEORRURALIDAD, (DES)ENCUENTRO DE SIGNIFICADOS}

Las tres apuestas socio-residenciales que hemos presentado son el resultado de diferentes proyectos vitales, diferentes modos de entender y experimentar lo urbano, lo rural y la relación entre ambos espacios y realidades. Sin embargo, la relevancia de estas tres apuestas no reside sólo en que representan la expresión de tres tipos de neorruralidades diferentes, sino en que contribuyen decididamente a la generación de distintos procesos económicos y sociales a partir de los cuales se van a perfilar el presente y futuro de la localidad, fomentando distintas dinámicas de desarrollo local y regional y, con ello, diferentes espacios rurales.

En el primer caso analizado, es fácil observar como la llegada de estos nuevos residentes no conlleva forzosamente la participación de estos en nuevas redes sociales, ni en el fortalecimiento del tejido socio-económico de la localidad, ya que la práctica totalidad de sus prácticas cotidianas siguen vinculadas a la ciudad. No queremos con esto decir que su llegada no afecte al devenir de la localidad, sino que su influencia 
se produce principalmente a través de procesos extralocales o muy ligados a estos. Esta influencia es especialmente observable en relación con la oferta y la demanda del sector inmobiliario (mayor dificultad de la población local, especialmente joven, para acceder a una vivienda en su localidad, revalorización de la vivienda local, etc.) y con cierto grado de reactivación del comercio local $^{8}$. Esta apuesta socio-residencial representa una estrategia residencial en la que el pragmatismo y la adecuación a unas determinadas necesidades juegan un papel decisivo en la elección del nuevo hogar y la nueva localidad de destino. Es una apuesta cuyo éxito pasa por la automovilidad de sus protagonistas y su constante desplazamiento a la ciudad, en la cual se ubica el propio desarrollo económico y social de estos. Representa, por tanto, una estrategia que se despliega por las áreas rurales que podríamos calificar de peri-urbanas y que va creando un espacio rural cada vez menos diferenciado del espacio urbano, del cual representa en muchos casos una extensión.

A pesar de compartir la misma necesidad de automovilidad, en el segundo tipo de neorruralidad observado, la apuesta socio-residencial realizada responde a un intento por evitar algunas de las consecuencias negativas de la experiencia urbana. Podríamos caracterizarla como la búsqueda de refugio y salvación a través de la privatización de la naturaleza y la experiencia de lo rural. No obstante, a pesar del deseo expreso de sus protagonistas de un cierto distanciamiento de la ciudad, el desarrollo de estos sigue esencialmente vinculado a ésta: trabajo, consumo, etc. De este modo, la llegada de estos neorrurales a la localidad se traduce en una progresiva renovación de la población y una reactivación de la vida social local a través de su participación en diversas actividades (festejos, etc.), más que en un fortalecimiento de su tejido económico. De hecho, esta expresión de la neorruralidad dibuja un espacio rural destinado esencialmente a un uso residencial, si bien debe al mismo tiempo preservarse el decorado rural que dota de significado al proyecto utópico que le subyace. Aquí surge la paradoja: ¿cómo compaginar este uso residencial con el mantenimiento en la localidad de aquellos aspectos de lo rural que alimentaron las imágenes de tranquilidad, conocimiento mutuo vecinal, naturaleza, etc.? Parece a priori esperable que una extensión de este uso del espacio rural conlleve precisamente una crisis progresiva de la imagen del pueblo que lo alentó.

Por último, hemos observado una tercera apuesta que refleja de un modo más palmario la crítica que le subyace de la ciudad y el modo de vida que ésta impone a sus habitantes. Esta apuesta neorrural implica no sólo el cambio del espacio residencial y su entorno, sino una transformación del modo de vida, ahora más vinculado a los ritmos de la naturaleza, a la vida de la localidad. Es un proyecto utópico cuya consecución exitosa ya no pasa por la automovilidad de sus protagonistas o su constante ir y venir entre la

\footnotetext{
${ }^{8}$ Esta reactivación puede a veces afectar al pequeño comercio local (cuando la llegada de población no es muy numerosa) o puede implicar la apertura de nuevas superficies comerciales (cuando la llegada se espera masiva en un período de tiempo más o menos breve). En este último caso, la situación del pequeño comercio local se encontraría en una situación paradójica.
} 
ciudad y el pueblo, sino por lo contrario, por la consecución de un sentimiento de arraigo y pertenencia a la localidad. Es, por tanto, un proyecto en el que la instrumentalización del espacio rural y la naturaleza han dado paso a una apropiación de carácter existencial. El espacio rural ya no es sólo un entorno o escenario de vida. Ahora es un proyecto de vida que pasa por vincular el presente y futuro de la vida de los neorrurales a la propia dinámica de desarrollo del lugar. De este modo, la llegada de estos neorrurales significa, por un lado, un repoblamiento y juvenilización de áreas muchas veces abocadas al despoblamiento progresivo. Por otro, una mayor integración de la economía local en procesos globales como la transformación del espacio rural en un espacio de consumo: restaurantes neotradicionales, venta de productos artesanales, casas rurales, etc. ${ }^{9}$

Para finalizar, es necesario decir que la tipología que acabamos de exponer no es exhaustiva ni rígida, sino que tiene vocación de ilustrar tres tipos ideales (siempre flexibles) de vuelta al campo, de experimentar la vida en la ciudad, de concebir lo rural y de practicar la neorruralidad. Representan, en definitiva, tres proyectos diferentes de vida. No obstante, como ya avanzamos, esta tendencia residencial introduce puntos de reflexión más allá de sus posibles expresiones. En primer lugar, nos muestra lo rural como una dimensión compleja que puede, al mismo tiempo, ser fuente de imágenes utópicas y distópicas y cuya apropiación puede ser instrumental o tener un carácter más existencial. Pero, en todo caso, nos muestra también una sociedad en la que lo urbano y lo rural son dos aspectos de una misma realidad estrechamente relacionados, que ya no es posible disociar. Podemos ver, por un lado, como ciertos tipos de neorruralidad fomentan un uso residencial del espacio rural, dejando éste a expensas de los procesos de desarrollo generados en la ciudad y, por otro, como ciertas expresiones de la neorruralidad surgen precisamente como respuesta a la actual experiencia de la vida urbana, si bien esta respuesta puede buscar un mayor o menor distanciamiento de la ciudad, tanto espacial como vivencial.

\section{REFERENCIAS BIBLIOGRÁFICAS}

Bourdieu, P. (2003), Las estructuras sociales de la economía, Barcelona, Anagrama.

Camarero, L. A. (1993), Del éxodo rural y del éxodo urbano. Ocaso y renacimiento de los asentamientos rurales en España, Madrid, Ministerio de Agricultura, Pesca y Alimentación.

Camarero, L. A. y J. Oliva (2002), "Urban Sprawl, Rural Turnaround and the Changing Shape of Utopia", XIII Congreso Mundial de Historia Económica Internacional, Buenos Aires.

\footnotetext{
${ }^{9}$ Transformación que no siempre va a ser fácilmente compatible con las actividades de la población local.
} 
Camarero, L. A., J. Oliva y M. R. Sampedro (1998), "Apuntes para el estudio de los nuevos paisajes sociales emergentes en la ruralidad Navarra", en Fernández, K. (ed.), Sociedad rural, desarrollo y bienestar, Pamplona, Pamiela, pp. 163-186.

Fielding, A. J. (1982), "Counterurbanisation in Western Europe", Progress in Planning 17: 3-52.

(1992), "Migration and culture", en Champion, A. y A. Fielding (eds.), Migration processes and patterns. vol. 1. Research progress and prospects, Londres, Belhaven, pp. 201-212.

Halfacree, K. (2001), 'Constructing the object: taxonomic practices, 'counterurbanisation' and positioning marginal rural settlement", International Journal of Population Geography, 7: 395-411.

(1997), "Contrasting roles for the post-productivist countryside. A postmodern perspective on counterurbanisation", en Cloke, P. y J. Little (eds.). Contested Countryside Cultures. Otherness, marginalisation and rurality, Londres, Routledge, pp. 70-93.

Halfacree K. y P. Boyle (1993), "The Challenge Facing Migration Research: The Case for a Biographical Approach", Progress in Human Geography, 17: 333-348.

Hoggart K. (1997), "Rural Migration and Counterurbanization in the European Periphery: The Case of Andalucía", Sociologia Ruralis 37, pp. 134-153.

Hoggart K. y A. Paniagua (2001), "The Restructuring of Rural Spain?", Journal of Rural Studies 17: 63-80.

Kontuly, T. (1998), "Contrasting the counterurbanisation experience in European nations", en Boyle, P. y K. Halfacree (eds.), Migration into rural areas. Theories and issues. Chichester, John Wiley, pp. 61-78.

Macnaghten, P. and J. Urry (1998), Contested natures, Londres, Sage.

Morin, E. (1968), “Culture de masse”, Encyclopaedia Universalis.

(1973), "Ciudad de luz y ciudad tentacular", en Morin, E. (1995), Sociología, Madrid, Tecnos, pp. 338347.

Mormont, M. (1998), "Belgique. À la recherché des espécifitiés rurales", en Jollivet (ed.), Vers un rural postindustriel. Rural et environnement dans huit pays européens, Paris, L'Harmattan.

Oliva, J. y L.A. Camarero (2002), Paisajes sociales y metáforas del lugar. Una exploración de la ruralidad itinerante en Navarra, Pamplona, Universidad Pública de Navarra.

Rivera, M. J. (2007a), "Migration to Rural Navarre: Questioning the Experience of Counterurbanisation", Tijdschrift voor Economische en Sociale Geografie 98, pp. 32-41.

(2007b), La ciudad no era mi lugar. Nuevos significados residenciales de la vuelta al campo en Navarra, Pamplona, Universidad Pública de Navarra.

Rivera, M. J. y M. Mormont (2006), "Néo-ruralité et les diferentes significations de la campagne", Colloque International Les mondes ruraux a l'epreuve des sciences sociales, Dijon.

RECIBIDO: 26/06/07

ACEPTADO: 26/06/08 